\title{
Resolution of Autoimmune Oophoritis after Thymectomy in a Myasthenia Gravis Patient
}

\author{
Esra Deniz Papatya Çakır1, Özlem Özdemir2, Erdal Eren1, Halil Sağlam1, Mehmet Okan2, Ömer Faruk Tarım1 \\ 1 Uludağ University School of Medicine, Pediatric Endocrinology, Bursa, Turkey \\ 2 Uludağ University School of Medicine, Pediatric Neurology, Bursa, Turkey
}

\section{ABSTRACT}

Myasthenia gravis (MG) is an autoimmune disorder characterized by autoantibodies against acetylcholine receptors. MG is generally an isolated disorder but may occur concomitantly with other autoimmune diseases. We describe an eighteen-year-old girl with MG who was admitted to our clinic with secondary amenorrhea and diagnosed as autoimmune oophoritis. Since her myasthenic symptoms did not resolve with anticholinesterase therapy, thymectomy was performed. After thymectomy, her menses have been regular without any hormonal replacement therapy. To our knowledge, this is the first report on a patient with autoimmune ovarian insufficiency and $M G$ in whom premature ovarian insufficiency resolved after thymectomy, without hormonal therapy.

Key words: Autoimmune oophoritis, myasthenia gravis, thymectomy

Conflict of interest: None declared

Received: 31.05 .2011
Accepted: 07.08.2011

\section{Introduction}

Myasthenia gravis (MG) is an autoimmune disorder characterized by autoantibodies against acetylcholine receptors (1). MG is generally an isolated disorder but a minority of patients may develop MG in conjunction with other autoimmune organ failures such as autoimmune thyroid diseases, rheumatoid arthritis, pernicious anemia and systemic lupus erythematosus $(2,3,4,5)$. Premature ovarian failure (POF) has been very rarely reported in association with MG. We report a case with MG in whom POF has resolved after thymectomy.

\section{Case Report}

An eighteen-year-old girl with a six-month-history of secondary amenorrhea was admitted to our pediatric endocrinology clinic. Her past medical history was remarkable for MG, presenting with ptosis and generalized muscle weakness developing at the end of the day. She was fifteen years old when she was diagnosed as having autoimmune MG. Her symptoms were partially resolved with pyridostigmine bromide $(120 \mathrm{mg} / \mathrm{day})$ and at the eleventh month of this therapy, prednisolone $(60 \mathrm{mg} /$ day) was added. After two months of prednisolone treatment, psychiatric symptoms appeared which were attributed to drug-induced bipolar affective disorder and steroid treatment was gradually discontinued. The antipsychotic olanzapine (15 mg/day) was started. Her menstrual cycles had started when she was twelve years old and were regular until thirteen months after

\section{Address for Correspondence}

Esra Deniz Papatya Çakır MD, Uludağ University School of Medicine, Pediatric Endocrinology, Bursa, Turkey Phone: +90 2244428143 E-mail: edpapatya@yahoo.com

OJournal of Clinical Research in Pediatric Endocrinology, Published by Galenos Publishing. 
the diagnosis of MG and at the third month of olanzapine therapy, when menstrual irregularity had appeared. Her family history was unremarkable. There was no pathologic finding in her physical examination. Her pubertal development was evaluated as Tanner stage 5.

Since neuroleptic drugs can increase serum prolactin levels and cause menstrual irregularity, the patient's prolactin level was checked and found normal. Her gonadotropin and inhibin B levels were in postmenapausal ranges (follicle stimulating hormone: $56.23 \mathrm{mlU} / \mathrm{mL}$, luteinizing hormone 25.43 $\mathrm{mlU} / \mathrm{mL}$, inhibin $\mathrm{B}<10 \mathrm{pg} / \mathrm{mL}$ ) and estrogen level was $18 \mathrm{pg} / \mathrm{mL}$. The patient's hormonal levels are shown chronologically from the beginning of the menstrual irregularity in Table 1. Primary ovarian insufficiency was evident with these hormonal levels. Her suprapubic pelvic ultrasonography revealed a large cystic formation $(57 \times 95 \times 112 \mathrm{~mm})$ in her left ovary. For etiological investigation of autoimmune POF (APOF), we checked antiovarian antibodies and the antibodies against the 21-hydroxylase enzyme. They were all negative. Acetylcholine receptor antibodies were found to be positive at the beginning of the myasthenic symptoms. Antithyroid peroxidase and antityroglobulin antibodies were also negative. We could not measure steroidogenic cell antibodies. The patient's myasthenic symptoms did not resolve with anticholinesterase therapy, and thymic enlargement was detected by thorax magnetic resonance imaging. Since there is a general consensus that patients with generalised MG between puberty and 60 years of age may benefit from thymectomy, this surgical procedure was performed and pathologic examination revealed follicular thymic hyperplasia. Three months after thymectomy, her regular menses started. Gonadotropin levels decreased to normal ranges, but her left ovarian cyst persisted. Six months after thymectomy, her left ovarian cyst was removed. Pathological diagnosis was benign mucinous cyst. Her menstrual bleeding has been regular since thymectomy, without any hormonal replacement therapy.

\section{Discussion}

POF is characterized by amenorrhea, hypoestrogenism and elevated serum gonadotropin levels in women younger than 40 years (6). Among a total of 266 POF patients, $4 \%$ of patients with spontaneous POF were diagnosed to have autoimmune oophoritis (AO) (7). An autoimmune mechanism was described in some patients with lymphocytic and plasma cell infiltration in developing follicles $(8,9,10)$. The only validated marker to detect $A O$ is the presence of steroidogenic cell autoantibodies $(7,11)$.

Coexistence of autoimmune ovarian failure and other autoimmune diseases was reported to be between $10 \%$ and $55 \%(6,12,13)$. APOF could be seen as a part of autoimmune polyglandular syndrome type 1 (APGST1) (72\%) and APGST2 $(10 \%)$ at the age of 40 years (14). It was also reported that $12-33 \%$ of women who presented with APOF had autoimmune thyroid disease as well $(13,15,16,17)$. APOF was also observed in patients with systemic lupus erythematosus and MG $(4,18,19,20)$. APOF and adrenal autoimmunity coexistence is the best known but not the most frequent association. Histological confirmation of APOF was first reported in a patient with autoimmune adrenal insufficiency (8). There was lymphocytic infiltration in the secondary and antral follicles, but primordial follicles were spared (21). Lymphocytic infiltration was most intense in the theca layer of the developing follicles and related with the intense luteinization of the follicles $(7,8,9,10)$. Ovarian biopsy is not recommended for the confirmation of the diagnosis in APOF. In one study (22), highly elevated total inhibin and inhibin B serum levels were reported in patients with APOF compared to patients with idiopathic POF and natural menopause. Increased inhibin $B$ level was thought to be a result of the initial preservation of granulosa cell functions. As the disease advances, ovaries can become atrophic. In our patient, inhibin B level was in postmenauposal range and estrogen levels were low. We thought that this postmenopausal inhibin $B$ level was the result of an advanced stage of the ovarian destruction in our patient. We did not perform ovarian biopsy at the time of diagnosis. However, six months after thymectomy, a benign mucinous ovarian cyst was removed. The pathology of the cyst showed no lymphocytic and plasma cell infiltration. At the time of the ovarian operation, our patient had been having regular menstrual bleeding and normal gonadotropin and sex steroid levels for six months.

\begin{tabular}{|c|c|c|c|c|}
\hline & Dec 12,2007 & Jan 8, 2009 & May 4, 2009 & Oct 7, 2009 \\
\hline FSH (mIU/mL) & 5.6 & 56.2 & 51.3 & 9.6 \\
\hline LH (mlU/mL) & 4.0 & 25.4 & 32.2 & 6.1 \\
\hline $\mathrm{E} 2(\mathrm{pg} / \mathrm{mL})$ & 10.0 & 18.0 & $<10$ & 68.0 \\
\hline Prolactin $(\mathrm{ng} / \mathrm{mL})(5.18-26 \mathrm{ng} / \mathrm{mL})$ & & 13.5 & & 12.0 \\
\hline Inhibin B (pg/mL) & & $<10$ & & \\
\hline 21-hydroxylase autoantibody (<0.5 U/ml) & & 1.0 & & \\
\hline
\end{tabular}

FSH: follicle-stimulating hormone, LH: luteinizing hormone, E2: estradio 
We thought that this was the reason we could not find lymphocytic and plasma cell infiltration representing $\mathrm{AO}$. However, it has been recently reported that lymphocytic and plasma cell infiltration may be absent and selective mononuclear cell infiltration free of lymphocytes may be observed in $\mathrm{AO}$ (23). Antibodies against steroid cell antigens obtained from adrenal tissue substrates are the most validated marker for the diagnosis of APOF that correlates with ovarian inflammation (7). We could only study anti-21hydroxylase and antiovarian antibodies and they were negative. The predictive value of the commercially available antiovarian antibody test is poor. One study (24) showed that these tests use animal ovarian tissues and have an unacceptably high false-positive rate.

Large ovarian cysts have been reported in several patients with AOF. As a result of follicular dysfunction, impaired negative feedback lead to elevated gonadotropin levels which overstimulate the ovarian tissues and lead to the development of large luteinized ovarian cysts $(25,26,27,28,29)$. Initially, we thought that our patient's large ovarian cyst had developed with this mechanism. However, we did not observe any regression in this large ovarian cyst after thymectomy although her regular menstruation resumed. On the other hand, thymectomy has been reported to induce autoimmune ovarian dysgenesis and autoimmune dacryoadenitis in mice. However, the significance of this finding in humans especially in the setting of MG is not clear (30).

Coexistence with another autoimmune disease is not a criterion for the diagnosis of APOF. However, our patient had primary ovarian failure and her ovarian insufficiency resolved after thymectomy. For this reason, we thought she had AO.

There is no controlled research about the treatment of AOF, but steroid therapy $20-40 \mathrm{mg} /$ day and cyclic estrogen-progesterone replacement therapy have been reported to be successful in several case reports and case series in adults (31). We did not use steroid therapy, because our patient had developed steroid-related bipolar affective disorder during the therapy for MG.

In 1969, Lundberg and Person reported a 25-year-old MG female patient with POF and her menstrual cycles became regular eight weeks after thymectomy (5). The authors thought that her ovarian failure had an autoimmune etiology. In 1993, a 27-year-old patient with POF and MG was reported to have had thymectomy one year after the initial diagnosis during which she received pyridostigmine and hormone replacement therapy. Spontaneous pregnancy occurred three years after thymectomy (32).

Our patient was not on hormonal replacement before and after thymectomy. Her regular menses started three months after thymectomy. To our knowledge, this is the first report on a patient with autoimmune ovarian insufficiency and MG in whom premature ovarian insufficiency resolved after thymectomy without hormonal therapy. We therefore suggest that treatment of MG including thymectomy if indicated may lead to resolution of the ovarian failure and hormonal therapy may not be necessary. If hormonal therapy had been introduced before MG was successfully treated; a trial of discontuniation of cyclic hormone replacement may reveal ovarian recovery.

\section{References}

1. Sarnat B.H. Disorders of neuromuscular transmission and of motor neurons. In Behrman, Kliegman, Jenson, eds. Nelson Textbook of Pediatrics. Philadelphia: Saunders; 2004:191-242.

2. Ryan MM, Jones HR. Myasthenia gravis and premature ovarian failure. Muscle Nerve 2004;30:231-233.

3. Bateman BG, Nunley WC Jr, Kitchin JD $3^{\text {rd }}$. Reversal of apparent premature ovarian failure in a patient with myasthenia gravis. Fertil Steril 1983;39:108-110.

4. Kuki S, Morgan RL, Tucci JR. Myasthenia gravis and premature ovarian failure. Arch Intern Med 1981;141:1230-1232.

5. Lundberg PO, Persson BH. Disappearance of amenorrhea after thymectomy. A case report. Acta Soc Med Ups 1969;74:206-208

6. Forges T, Monnier- Barbarino P, Faure GC, Bene MC. Autoimmunity and antigenic targets in ovarian pathology. Hum Reprod Update 2004;10:163-175.

7. Bakalov VK, Anasti JN, Calis KA, Vanderhoof VH, Premkumar A, Chen S, Furmaniak J, Smith BR, Merino MJ, Nelson LM. Autoimmune oophoritis as a mechanism of follicular dysfunction in women with $46, X X$ spontaneous premature ovarian failure. Fertil Steril 2005:84:958-965

8. Irvine WJ, Chan MM, Scarth L, Kolb FO, Hartog M, Bayliss RI, Drury Ml. Immunological aspects of premature ovarian failure associated with idiopathic Addison's disease. Lancet 1968;2:883-887.

9. Bannatyne P, Russel P, Shearman RP. Autoimmune oophoritis: a clinicopathologic assesment of 12 cases. Int Gynecol Pathol 1990;9:191-207.

10. Gloor E, Hurlimann J. Autoimmune oophoritis. Am J Clin Pathol 1984:81:105-109.

11. Welt CK. Autoimmune oophoritis in the adolescent. Ann N Y Acad Sci 2008;1135:118-122.

12. Coulam JB. The prevalance of autoimmune disorders among patients with primary ovarian failure. Am J Reprod Immunol 1983;4:63-66.

13. de Moraes-Reuhsen M, Blizzard RM, Garcia-Bunuel R, Jones GS. Autoimmunity and ovarian failure. Am J Obstet Gynecol 1972;112:693-703.

14. Perheentupa J. APS-1/APECED: the clinical disease and therapy. Endocrinol Metab Clin North Am 2002;31:295-320.

15. Rebar RW, Erickson GF, Yen SS. Idiopathic premature ovarian failure: clinical and endocrine characteristics. Fertil Steril 1982:37:35-41.

16. Alper MM, Garner PR. Premature ovarian failure: its relationship to autoimmune disease. Obstet Gynecol 1985;66:27-30.

17. Betterle C, Rossi A, Dalla Pria S, Artifoni A, Pedini B, Gavasso S, Caretto A. Premature ovarian failure : autoimmunity and natural history. Clin Endocrinol (Oxf) 1993;39:35-43.

18. Pekonen F, Seigberg R, Makinen T, Miettinen A, Yli-Korkala O Immunological disturbances in patients with premature ovarian failure. Clin Endocrinol (Oxf) 1986;25:1-6.

19. LaBarbera AR, Miller MM, Ober C, Rebar RW. Autoimmune etiology in premature ovarian failure. Am J Reprod Immunol Microbiol 1988;16:115-122.

20. Escobar ME, Cigorraga SB, Chiauzzi VA, Charreau EH, Rivarola MA. Development of the gonadotrophic resistant ovary syndrome in myasthenia gravis: suggestion of similar autoimmune mechanisms. Acta Endocrinol (Copenh) 1982:99:431-436. 
21. Sedmak DD, Hart WR, Tubbs RR. Autoimmune oophoritis: a histopathologic study of involved ovaries with immunologic characterization of the mononuclear cell infiltrate. Int J Gynecol Pathol 1987:6:73-81.

22. Tsigkou A, Marzotti $S$, Borges $L$, Brozzetti $A$, Reis F, Candeloro $P$, Luisa Bacosi M, Bini V, Petraglia F, Falorni A. High seum inhibin concentration discriminates autoimmune oophoritis from other forms of primary ovarian insufficiency. J Clin Endocrinol Metab 2008;93:1263-1269.

23. La Marca A, Brozzetti A, Sighinolfi G, Marzotti S, Volpe A, Falomi A. Primary ovarian insufficieny : autoimmune causes. Curr Opin Obstet Gynecol 2010;22:277-282.

24. Novosad JA, Kalantaridou SN, Tong ZB, Nelson LM. Ovarian antibodies as detected by indirect immunofluorescence are unreliable in the diagnosis of autoimmune premature ovarian failure: a controlled evaluation. BMC Womens Health 2003;3:2.

25. Biscotti CV, Hart WR, Lucas JG. Cystic ovarian enlargement resulting from autoimmune oophoritis. Obstet Gynecol 1989;74:492-495.

26. Burrell LM, Murdoch A, Angus B, White MC. Autoimmune ovarian failure with elevated serum levels of luteinizing hormone and enlarged ovaries. Case report. Br J Obstet Gynaecol 1990:97:362-364.
27. Lonsdale RN, Roberts PF, Trowell JE. Autoimmune oophoritis associated with polycystic ovaries. Histopathology 1991;19:77-81

28. Welt CK, Hall JE, Adams JM, Taylor AE. Relationship of estradiol and inhibin to the follicle-stimulating hormone variability in hypergonadotrophic hypogonadism or premature ovarian failure. J Clin Endocrinol Metab 2005;90:826-830.

29. Welt CK, Falorni A, Taylor AE, Martin KA, Hall JE. Selective theca cell dysfunction in autoimmune oophoritis results in multifollicular development, decreased estradiol, and elevated inhibin B levels. J Clin Endocrinol Metab 2005:90:3069-3076.

30. del Rio R, Sun Y, Alard P, Tung KS, Teuscher C. H2 control of natural $T$ regulatory cell frequecy in the lymph node correlates with susceptibility today 3 thymectomy-induced autoimmune disease. J Immunol 2011;186:382-389.

31. Kalantaridou SN, Braddock DT, Patronas NJ, Nelson LM. Treatment of autoimmune premature ovarian failure. Hum Reprod 1999:14:1777-1782.

32. Chung TK, Haines CJ, Yip SK. Case report: spontaneous pregnancy following thymectomy for myasthenia gravis associated with premature ovarian failure. Asia Oceania J Obstet Gynaecol 1993;19:253-255 